\title{
A 3 year retrospective study on gestational trophoblastic disease in a government obstetrical tertiary care centre
}

\author{
Veeraraghavan Gurusamy ${ }^{1 *}$, Madurai Padmanabhan Kanchana ${ }^{1}$, \\ Lakshmi Narasimhan Srinivasan ${ }^{2}$
}

${ }^{1}$ Department of Pathology, Institute of Obstetrics and Gynecology, Madras Medical College, Chennai, India
${ }^{2}$ Department of Medical Oncology, Institute of Obstetrics and Gynecology, Madras Medical College, Chennai, India

Received: 8 October 2016

Revised: 9 October 2016

Accepted: 03 November 2016

*Correspondence:

Dr. Veeraraghavan Gurusamy,

E-mail: gvrvishwa@gmail.com

Copyright: (c) the author(s), publisher and licensee Medip Academy. This is an open-access article distributed under the terms of the Creative Commons Attribution Non-Commercial License, which permits unrestricted non-commercial use, distribution, and reproduction in any medium, provided the original work is properly cited.

\begin{abstract}
Background: The aim of this study is to assess the post diagnostic outcome of Gestational Trophoblastic Disease, a heterogeneous group of disorders, in a government obstetrical tertiary care centre.

Methods: The study was conducted in the Institute of Obstetrics \& Gynecology, Madras Medical College as a retrospective study. A total of 75 cases were studied over a 3 year period from January 2012 to December 2015. The parameters which were studied included age group, antecedent pregnancy, beta hCG values, histopathological types and Treatment profile.

Results: Of the 75 cases, 55 cases (73\%) were in the 21-39 age group. The spectrum of disorders that were studied included 69 cases of complete mole, 2 cases of partial mole, 1 case of twin pregnancy with single live foetus and partial mole, 1 case of triplet pregnancy with two live foetuses and partial mole, 1 case of epithelioid trophoblastic tumour and 1 case of choriocarcinoma. Of the 75 cases, 16 cases underwent chemotherapy. No mortality was observed during the study period.

Conclusions: Close monitoring and follow up with beta hCG values is of utmost importance in the management of Gestational trophoblastic disease. In cases of gestational trophoblastic neoplasia (GTN), WHO/FIGO scoring should be done and managed with chemotherapy according to the risk assessment.
\end{abstract}

Keywords: Beta hCG, Choriocarcinoma, Chemotherapy, Epithelioid trophoblastic tumour, Gestational trophoblastic disease, Gestational trophoblastic neoplasia

\section{INTRODUCTION}

Gestational trophoblastic disease is a group of disorders characterised by abnormal proliferation of morphologically abnormal trophoblastic tissue. The spectrum of gestational trophoblastic disease includes the hydatidiform moles (complete, partial and invasive mole), trophoblastic tumour like lesions (exaggerated placental site and placental site nodule) and trophoblastic neoplasia (choriocarcinoma, placental site trophoblastic tumour and epithelioid trophoblastic tumour). ${ }^{1}$
While the management of these lesions have largely been medical, the differences in the clinical behaviour of each of these lesions warrant the need for accurate diagnosis and appropriate management. Beta-hCG, a wellrecognized marker of trophoblast, is of immense value in the diagnosis and follow up of gestational trophoblastic disease. The aim of this retrospective study is to analyse the post diagnostic outcome of this heterogeneous disease group over a 3 year period in a government obstetrical and gynaecological tertiary care centre. 


\section{METHODS}

The retrospective study was done in the Department of Pathology and Department of Medical Oncology, Institute of Obstetrics and Gynecology, Egmore, Chennai. For this study, 75 cases which were histologically diagnosed to have gestational trophoblastic disease in the department of pathology from January 2013 to December 2015 were selected and their respective medical case records from the department of medical oncology were accessed. Patients who were diagnosed in other hospitals and receiving treatment in this institute were excluded. Patients who were diagnosed in this institute and receiving treatment in other hospitals were also excluded.

All the cases had detailed clinical history which included age, gravidity and parity and clinical signs and symptoms, detailed physical examination findings, routine blood investigations which included complete blood count, blood grouping and typing, liver function tests and renal function tests. Ultra sonogram and chest $\mathrm{X}$-ray findings were available for all the patients.

Baseline beta-hCG values were available for all but 4 patients. Subsequent follow-up beta-hCG values in accordance with the FIGO guidelines were taken and noted. The treatment given and the dates for subsequent follow up and review were noted for all patients. WHO scoring was done and noted for all cases with gestational trophoblastic neoplasia. All patients and their spouses were given counselling and advised contraception in the form of oral contraceptive pills. All the collected data were then analysed.

\section{RESULTS}

75 cases of gestational trophoblastic disease were studied over a period of 3 years from January 2013 to December 2015. Of these, majority (73\%) occurred in the 21-39 age group; there was only one woman who was in the 40 years of age and above group who had gestational trophoblastic disease (Figure 1). The mean age was 23.5 years and ranged from 16 years to 40 years of age.

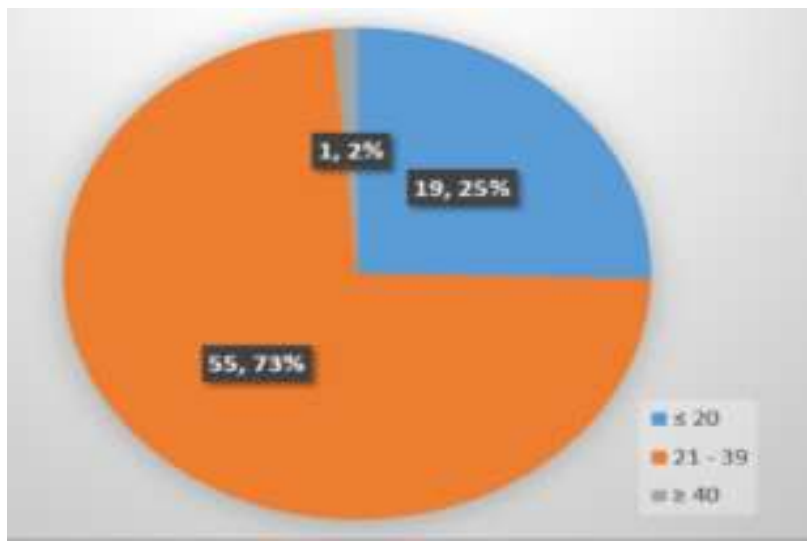

Figure 1: Age group.
Histopathologically, complete mole constituted the major proportion $(92 \%)$ of the group, followed by partial mole $(2.7 \%)$. One case with a history of in vitro fertilization had triplet pregnancy with partial mole and coexistent two live foetuses until term. One case had twin gestation with partial mole and coexistent single live foetus until term. One case was diagnosed to have epithelioid trophoblastic tumour. One case of choriocarcinoma was diagnosed on the basis of clinical and radiological evidence.

Most of the women (48\%) had no prior pregnancy and $32 \%$ of women had prior full term dilvery. $17 \%$ of women had prior abortion while $3 \%$ women had prior molar pregnancy (Figure 2). Baseline beta-hCG values of more than 1 lakh $\mathrm{mIU} / \mathrm{ml}$ was found in 52 cases $(69 \%)$ whereas only 1 case $(2 \%)$ who was diagnosed with epithelioid trophoblastic tumour had value less than 1000 $\mathrm{mIU} / \mathrm{ml}$. Baseline beta-hCG values were not available for 4 cases $(5 \%)$ (Figure 3 ).

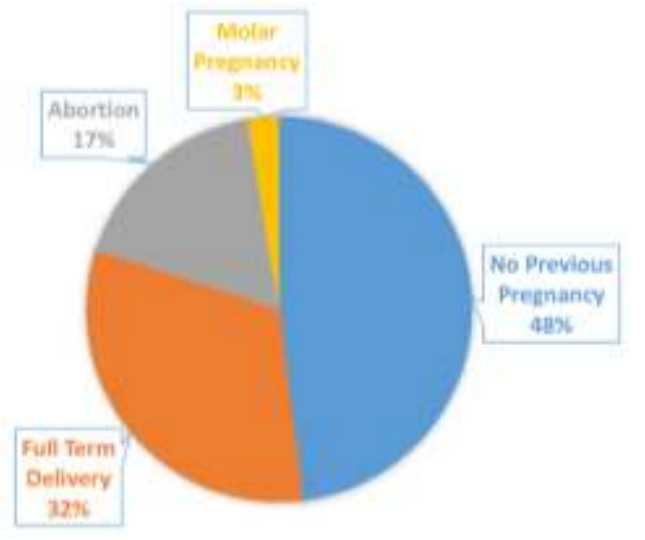

Figure 2: Antecedent pregnancy.

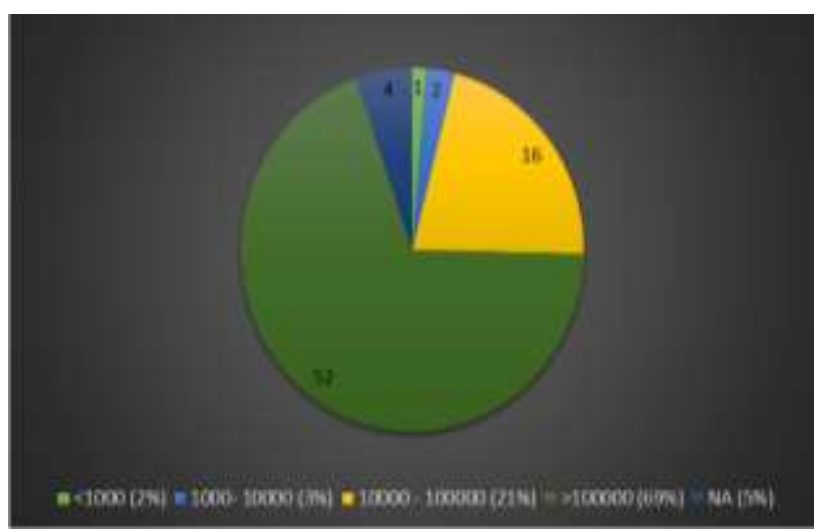

Figure 3: Baseline beta-hCG values.

Suction curettage was the procedure performed in all hydatidiform moles. Follow-up beta-hCG values were available for all patients with the exception of dropouts. 52 cases of complete mole were cured with suction curettage alone with normalization of beta-hCG levels within 6 months. 
12 cases of complete mole and 2 cases of partial mole comprising about $18.7 \%$ of the disease group, with rising or persistently elevated beta-hCG levels required single agent chemotherapy with methotrexate along with leucovorin. Of these, 2 cases of complete mole and 1 case of partial mole were also given pulsed actinomycin D as salvage therapy due to persistent low levels of beta-hCG $(\leq 50 \mathrm{mIU} / \mathrm{ml})$ following methotrexate regimen. Uterine arteriovenous malformation is a rare complication following trophoblastic disease ${ }^{2}$. It was observed in one case of complete mole who underwent chemotherapy and was successfully managed with embolization. All 14 cases achieved normalization of beta-hCG. (Figure 4).

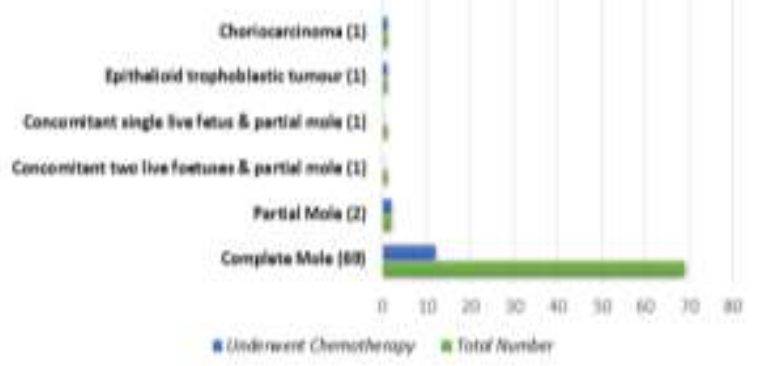

Figure 4: Patients who required chemotherapy.

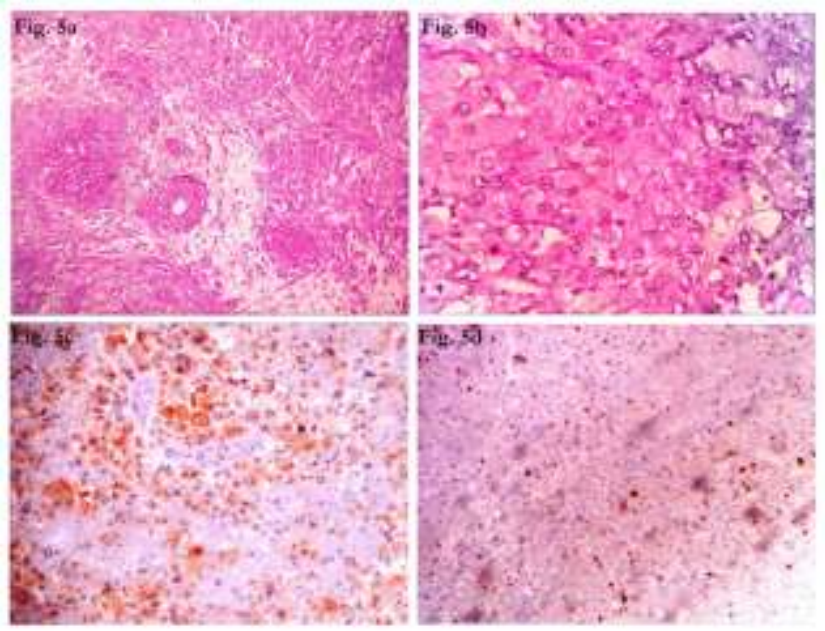

Figure 5 a, b: Round to polygonal atypical intermediate trophoblastic cells arranged in sheets and clusters; c: p63 strong positivity; d: Ki-67 index $>12 \%$.

Lower uterine segment caesarean section (LSCS) with manual removal of placenta was performed in the cases of triplet pregnancy with two live foetuses and partial mole and twin pregnancy with single live foetus and partial mole. In both these instances, the women were diagnosed to have concomitant molar pregnancy in the first trimester, but were willing to continue full term. Both cases were followed up with beta-hCG levels which remained undetectable at the end of their follow-up period. (Figure 6).
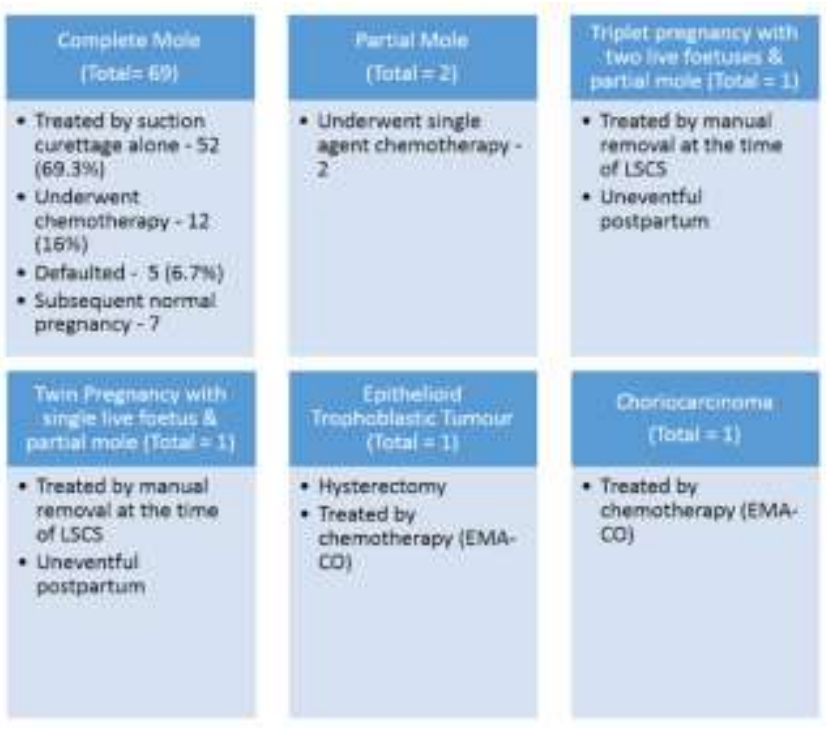

Figure 6: Treatment profile.

In one instance, a woman had a history of amenorrhea, abdominal pain and beta-hCG level of $421.4 \mathrm{mIU} / \mathrm{ml}$. MRI revealed a heterogeneously enhancing lesion in myometrium, lateral wall of cervix and anterior wall of vagina with gross ascites. Hysterectomy was done and post-operative histopathological examination and immunohistochemistry (p63, ki-67) proved it to be epithelioid trophoblastic tumour (ETT) (Figure 5). The woman had antecedent full term normal vaginal delivery, 1 year prior to hysterectomy. She was treated with EMA$\mathrm{CO}$ multi agent chemotherapy (etoposide, methotrexate with leucovorin rescue and actinomycin $\mathrm{D}$ given on day 1 and 2 and cyclophosphamide and vincristine given on day 8) and was followed up for two years. She had undetectable beta-hCG levels at the end of her follow up period (Figure 6). With less than 100 cases of ETT reported in the literature worldwide, this rare case report from our institute had been published. ${ }^{3}$

One case was clinically suspected to have ruptured ectopic pregnancy and laparotomy was done. Peroperatively, 1.5 litres of hemoperitoneum was evacuated. Hysterotomy was done and suction evacuation was performed and the material was sent for histopathological examination. However histopathological examination failed to reveal molar villi even after thorough sampling of the entire tissue. Postoperatively, the patient had rising beta-hCG levels after 1 month and was started on single agent chemotherapy with Methotrexate and leucovorin rescue. CT chest revealed multiple pulmonary nodules, suggestive of metastases and in correlation with the elevated beta-hCG, metastases from choriocarcinoma was diagnosed and the patient was started on multi agent chemotherapy with EMA-CO regimen following which beta-hCG values were normalized (Figure 6).

Most of the cases (55\%) were followed up for a period of more than 6 months. However 5 cases $(6.7 \%)$ who were 
diagnosed with complete mole defaulted within 2 months of follow up and could not be traced, whereas all the high risk cases (WHO score $\geq 7$ ) were followed up for a period of at least 1 year (Figure 6). No mortality was observed. 7 women who were diagnosed to have complete mole even proceeded to have normal subsequent pregnancy after the completion of their follow up period.

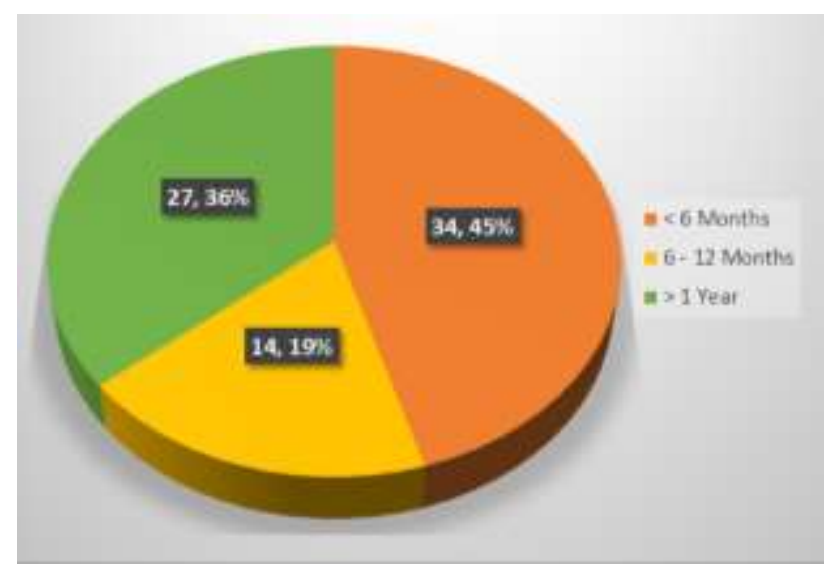

Figure 7: Follow-up period.

\section{DISCUSSION}

Gestational trophoblastic disease is a unique group with its varied clinical and histological presentation ranging from benign lesions to frank malignancy with distant metastases. With the increasing use of ultra-sonogram in the first trimester, availability of sensitive beta-hCG assays and well recognized histological and immunohistochemical features of the spectrum of diseases, an accurate diagnosis can be arrived at.

In cases of molar pregnancies, a baseline beta-hCG level is essential for comparison with the post-evacuation values. In line with the FIGO recommendations, weekly beta-hCG levels should be monitored post evacuation, until it becomes undetectable, followed by two values at weekly intervals. This is followed by monthly beta-hCG level monitoring for 6 months and then every 2 months for a further 6 months. ${ }^{4}$

Pregnancy should be avoided for 6 months postnormalization of beta-hCG values and hence contraception is advised. This is mainly done to differentiate a rising beta-hCG due to persistent disease from that of a rising beta-hCG due to a subsequent pregnancy. The use of oral contraceptive pills (OCPs) is advised because they suppress the endogenous luteinising hormone levels which when present interferes with the measurement of beta-hCG. ${ }^{5}$ Furthermore OCPs have been found to be safe during post molar follow-up period. ${ }^{6}$

The diagnosis of gestational trophoblastic neoplasia (GTN) is made on the basis of four persistently elevated beta-hCG levels or a sequential rise of beta-hCG for 2 weeks and lung metastases as diagnosed by imaging. ${ }^{4}$
Histological diagnosis is not a pre-requisite according to FIGO guidelines. Nonetheless, it can be a useful predictor of the disease prognosis. WHO scoring for risk stratification should be done for all cases of gestational trophoblastic neoplasia because the management differs for the low risk and high risk groups. ${ }^{7}$ Low risk GTNs are managed with single agent chemotherapy using methotrexate or actinomycin-D. High risk patients are managed with combination chemotherapy EMA-CO regimen or a variant of it. ${ }^{8}$ Pregnancy should be avoided for at least 1 year following the completion of chemotherapy and oral contraceptives are prescribed for the duration. ${ }^{9}$

Gestational trophoblastic neoplasias are no longer a grave threat it used to be. The advent of chemotherapy has drastically reduced the mortality rate. ${ }^{10,11}$ The survival rate approaches $100 \%$ in low risk GTN (WHO score $\leq 6$ ). Chemotherapy has been so effective that the survival rate for high risk GTN (WHO score $\geq 7$ ) is more than $90 \%$ even in the presence of distant metastases. ${ }^{4}$ When managed appropriately, mortality can be significantly low as evidenced by the zero mortality in this study. However GTN is notorious for its late recurrence. In this setting, the post diagnostic follow up and the importance of betahCG levels cannot be overemphasized ${ }^{12}$. However in a populous country like India, follow-up could prove to be a challenge.

\section{CONCLUSION}

Post diagnostic work up of gestational trophoblastic disease should involve close monitoring and follow up of patients with beta-hCG values. Any pregnancy event should be followed up with beta-hCG values at 6 weeks postpartum. In cases of gestational trophoblastic neoplasia, WHO/FIGO scoring should be done and managed according to the risk assessment. The importance of contraception and follow up should be emphasized to patients. In order to reduce the rate of defaulters, a national level or state level registry could be started to monitor the patients follow up, because trophoblastic neoplasia could prove to be rapidly fatal, unless managed appropriately with chemotherapy.

Funding: No funding sources Conflict of interest: None declared

Ethical approval: Not required

\section{REFERENCES}

1. Mazur MT, Kurman RJ. Gestational Trophoblastic Tumors and Related Tumor-Like Lesions, Blaustein's pathology of the female genital tract. Springer; 2011; 1076.

2. Yela DA, Yoneda J, Brasil L. Uterine arteriovenous malformation after gestational trophoblastic disease: a report of two cases. J Reprod Med. 2014;59(78):417-20. 
3. Manoharan J, Padmanaban KM. Epithelioid trophoblastic tumour: a rare case with an unusual presentation. J Evolution Med Dent Sci. 2016;5(57):3970-2.

4. Ngan HY, Kohorn EI, Cole LA, Kurman RJ, Kim SJ, Lurain JR, et al. Trophoblastic disease. Int J Gynaecol Obstet. 2012;119 Suppl 2:S130-6. Erratum in: Int J Gynaecol Obstet. 2014;125(1):93.

5. Lurain, JR. Gestational trophoblastic disease I: epidemiology, pathology, clinical presentation and diagnosis of gestational trophoblastic disease, and management of hydatidiform mole. Am J Obstet Gynecol. 2010;203:531-9.

6. Costa HL, Doyle P. Influence of oral contraceptives in the development of post-molar trophoblastic neoplasia--a systematic review. Gynecol Oncol. 2006;100(3):579-85.

7. Ngan HY, Seckl MJ, Berkowitz RS, Xiang Y, Golfier F, Sekharan PK, Lurain JR. Update on the diagnosis and management of gestational trophoblastic disease. Int $\mathrm{J}$ Gynaecol Obstet. 2015;131(2):S123-6.

8. Lurain JR. Gestational trophoblastic disease II: classification and management of gestational trophoblastic neoplasia. Am J Obstet Gynecol. 2011;204(1):11-8.

9. Lan Z, Hongzhao S, Xiuyu Y, Yang X. Pregnancy outcomes of patients who conceived within 1 year after chemotherapy for gestational trophoblastic tumor: a clinical report of 22 patients. Gynecol Oncol. 2001;83(1):146-8.

10. Martin BH, Kim JH. Changes in gestational trophoblastic tumors over four decades. A Korean experience. J Reprod Med. 1998;43(1):60-8.

11. Seckl MJ, Sebire NJ, Berkowitz RS. Gestational trophoblastic disease. Lancet. 2010;376(9742):71729.

12. Seckl MJ, Sebire NJ, Fisher RA, Golfier F, Massuger L, Sessa C; ESMO Guidelines Working Group. Gestational trophoblastic disease: ESMO Clinical Practice Guidelines for diagnosis, treatment and follow-up. Ann Oncol. 2013;24(6):vi39-50.

Cite this article as: Veeraraghavan G, Kanchana MP, Srinivasan LN. A 3 year retrospective study on gestational trophoblastic disease in a government obstetrical tertiary care centre. Int J Reprod Contracept Obstet Gynecol 2016;5:4405-9. 